\title{
Structural, magnetic, and acidic properties of cobalt ferrite nanoparticles synthesised by wet chemical methods
}

\author{
Manju KURIAN ${ }^{a,}{ }^{*}$, Smitha THANKACHAN ${ }^{b}$, Divya S. NAIR ${ }^{a}$, Aswathy E. K. ${ }^{a}$, \\ Aswathy $\mathrm{BABU}^{a}$, Arathy THOMAS ${ }^{b}$, Binu KRISHNA K. T. ${ }^{b}$ \\ ${ }^{a}$ Department of Chemistry, Mar Athanasius College, Kothamangalam-686666, India \\ ${ }^{b}$ Department of Physics, Mar Athanasius College, Kothamangalam-686666, India
}

Received: January 12, 2015; Revised: February 26, 2015; Accepted: March 10, 2015

(C) The Author(s) 2015. This article is published with open access at Springerlink.com

\begin{abstract}
A detailed investigation on the effect of preparation method on the structural, magnetic, and acidic properties of cobalt ferrite nanoparticles prepared by sol-gel and co-precipitation is presented. Citric acid and ethylene glycol were used as gelling agents, while sodium hydroxide and aqueous ammonia were used as precipitating agents. The resulting ferrites were calcined at $450{ }^{\circ} \mathrm{C}$ and $750{ }^{\circ} \mathrm{C}$. Sharper X-ray diffraction (XRD) peaks were observed for the samples calcined at $750{ }^{\circ} \mathrm{C}$, indicating greater crystallinity of the samples calcined at higher temperature. Average crystallite sizes fell in the ranges of 7.1-21.1 nm and 30.4-42.1 nm for the samples calcined at $450{ }^{\circ} \mathrm{C}$ and $750{ }^{\circ} \mathrm{C}$, respectively. The infrared spectra revealed two main absorption bands, the high frequency band $v_{1}$ around $600 \mathrm{~cm}^{-1}$ and the low frequency band $v_{2}$ around $400 \mathrm{~cm}^{-1}$ arising from stretching vibrations of the oxygen bond with the metal in the tetrahedral (A) and octahedral (B) sites in the spinel lattice. Agglomeration of particles was observed in the scanning electron microscopy (SEM) images. Magnetic parameters of $\mathrm{CoFe}_{2} \mathrm{O}_{4}$ nanoparticles greatly depended on calcination temperature and preparation techniques. Ammonia temperature programmed desorption (TPD) measurements indicated that weak acid sites predominate medium strength sites, while the number of strong acid sites is the least. Cumulative acidity decreased for the samples calcined at higher temperature. The results underline the effect of preparation conditions on the morphology, crystallite size, and magnetic properties of nano ferrites.
\end{abstract}

Keywords: nano ferrites; sol-gel technique; co-precipitation; magnetic property; surface acidity

\section{Introduction}

Cobalt ferrite nanoparticles have been the subject of recurrent research because of their potential industrial and biomedical applications. They crystallize into inverse spinel structure, where the divalent $\mathrm{Co}^{2+}$ ions

\footnotetext{
* Corresponding author.

E-mail: mk@macollege.in, manjukurian@gmail.com
}

are located in the octahedral positions, while half of the $\mathrm{Fe}^{3+}$ ions are situated at the tetrahedral sites and the other half at the octahedral sites. The small dimensions of the material generate novel chemical and physical properties like high coercivity $\left(H_{\mathrm{c}}\right)$, moderate saturation magnetization $\left(M_{\mathrm{s}}\right)$, exceptional chemical stability, and high mechanical hardness. These properties make it a promising material for highdensity magnetic recording, permanent magnets, magnetic fluids, photo-magnetic material, and gas 
sensing [1-3]. The size reduction of a magnetic material leads to novel properties like superparamagnetism as compared to bulk material due to small volume [4]. It is known that magnetic ferrite nanoparticles can be used extensively for drug delivery, cell labeling and sorting, magnetic resonance imaging and sensing, cell thawing agents, as well as catalytic applications [5-8].

$\mathrm{CoFe}_{2} \mathrm{O}_{4}$ particles with spinel structure show a variety of novel properties that vary with the nature of the cations, their charge, and site distribution amongst tetrahedral and octahedral sites. The type of cations and their distribution between two interstitial sites in spinel ferrites can be tuned by controlling the experimental conditions during synthesis. For this reason, different experimental methods have been used in the production of ferrite nanoparticles such as sol-gel techniques $[9,10]$, co-precipitation method [11,12], microwave sintering method [13], hydrothermal method [14], spray-spin-heating-coating method [15], and sonochemical method [16]. Of the different techniques, co-precipitation and sol-gel methods are promising techniques for preparing nano ferrites in bulk scale due to the production of homogeneous particles. Co-precipitation method with constant $\mathrm{pH}$ has been widely used because of the high crystallinity, homogeneity, and good textural properties of the materials produced. Sol-gel technique has become very popular recently for the preparation of a variety of mixed-metal oxides, nanomaterials, and nanoporous oxides due to the high chemical homogeneity, low processing temperatures, and the possibility of controlling the size and morphology of particles. It has been demonstrated that the sol-gel process offers considerable advantages such as better mixing of the starting materials and excellent chemical homogeneity in the final product $[17,18]$.

In the present study, cobalt ferrite nanoparticles are prepared through two co-precipitation methods as well as two sol-gel auto combustion methods, and a comparison is made on these methods by studying the structural properties of nanoparticles produced. The effect of heat treatment is studied by calcining the obtained samples at two different temperatures. The obtained nanoparticles are characterized by different standard techniques such as X-ray diffraction (XRD), Fourier transform infrared (FTIR) spectroscopy, vibrating sample magnetometer (VSM), and scanning electron microscopy (SEM). The acid site distribution of the prepared samples also has been quantified using temperature programmed desorption (TPD) of ammonia for possible use as solid acid catalysts.

\section{Materials and methods}

$\mathrm{CoFe}_{2} \mathrm{O}_{4}$ was prepared by two co-precipitation methods as well as two sol-gel auto combustion methods. Pure $\mathrm{Fe}\left(\mathrm{NO}_{3}\right)_{3} \cdot 9 \mathrm{H}_{2} \mathrm{O} \quad(99.9 \%)$, $\mathrm{Co}\left(\mathrm{NO}_{3}\right)_{2} \cdot 6 \mathrm{H}_{2} \mathrm{O}$, ethylene glycol, citric acid, sodium hydroxide, and ammonia solution from Merck, India, were used as starting materials. In the first sol-gel auto combustion method, an aqueous solution of citric acid was mixed with metal nitrate solution followed by addition of appropriate amount of ammonia solution until a $\mathrm{pH}$ of 7 was reached. This solution was heated on a magnetic stirrer at $90{ }^{\circ} \mathrm{C}$ with constant stirring until the resulting gel foamed. It was then heated in a mantle at $150{ }^{\circ} \mathrm{C}$ for spontaneous ignition and the loose powder was then crushed well. In the second sol-gel method, the metal nitrates dissolved in minimum amount of ethylene glycol used as precursor solution. In the first co-precipitation method, calculated amounts of $\mathrm{Fe}\left(\mathrm{NO}_{3}\right)_{3} \cdot 9 \mathrm{H}_{2} \mathrm{O}$ and $\mathrm{Co}\left(\mathrm{NO}_{3}\right)_{2} \cdot 6 \mathrm{H}_{2} \mathrm{O}$ were weighed accurately and dissolved in doubly distilled water. The precipitation was carried out at controlled $\mathrm{pH}(\sim 9.5)$ using 1:1 $\mathrm{NH}_{3}$ solution. It was then heated at $95{ }^{\circ} \mathrm{C}$ with constant stirring for $4 \mathrm{~h}$ followed by oxidation using $30 \% \mathrm{H}_{2} \mathrm{O}_{2}$. The precipitated ferrite was washed well, dried in an air oven at $120{ }^{\circ} \mathrm{C}$, and crushed well. In the second co-precipitation method, the precipitation was done by $10 \mathrm{M} \mathrm{NaOH}$ using the same procedure as in the previous method with the exclusion of $\mathrm{H}_{2} \mathrm{O}_{2}$ addition. All samples were calcined at $450{ }^{\circ} \mathrm{C}$ and $750{ }^{\circ} \mathrm{C}$ for $4 \mathrm{~h}$ and are hereafter designated as SC I, SC II, SE I, SE II, CA I, CA II, CS I, and CS II.

Phase identification of the samples was performed using Rigaku MiniFlex 600 X-ray diffractometer with $\mathrm{Cu} \mathrm{K \alpha}(\lambda=1.5406 \AA)$ as the radiation source. The average crystallite size $(D)$ of the ferrite particles was determined from XRD using the Debye-Scherer formula $D_{(h k l)}=0.9 \lambda /(\beta \cos \theta)$, where $D_{(h k l)}$ is the average crystallite size (nm); $\lambda$ is the wavelength (nm); $\beta$ is the full width at half maximum (radian); and $\theta$ is the Bragg angle. The lattice parameter $a$ was calculated using the relation $a=d\left(h^{2}+k^{2}+l^{2}\right)^{1 / 2}$. Since each primitive unit cell of the spinel structure contains 8 molecules, the value of X-ray density $\left(d_{\mathrm{X}}\right)$ was calculated according to the relation $d_{\mathrm{X}}=8 \mathrm{M} /\left(\mathrm{Na}^{3}\right)$, where $N$ is the Avogadro number $\left(6.022 \times 10^{23} \mathrm{~mol}^{-1}\right)$; 
$M$ is the molecular weight of the sample; and $a$ is the lattice parameter. The measured density or bulk density $\left(d_{\mathrm{B}}\right)$ was calculated from mass and bulk volume of the sample pellets using the formula $d_{\mathrm{B}}=m /\left(\pi r^{2} h\right)$, where $m$ is the mass of the sample taken; $r$ is the radius of the sample pellet; and $h$ is the height of the pellet. From the bulk density and X-ray density, porosity of each sample was determined using the relation $P=1-d_{\mathrm{B}} / d_{\mathrm{X}}$. The surface morphology of the prepared samples was evaluated using JEOL JSM-6390 LV scanning electron microscope with a dynamic light scattering technique. The Fourier transform infrared studies were carried out in $\mathrm{KBr}$ medium using Thermo Nicolet, Avatar 370 model FTIR spectrometer in the range of 400 $4000 \mathrm{~cm}^{-1}$ with a resolution of $4 \mathrm{~cm}^{-1}$. Magnetic measurements were carried out using Lakeshore VSM 7410 at room temperature. Temperature programmed desorption of ammonia (TPD- $\mathrm{NH}_{3}$ ) of the samples was carried out in a reactor packed with $0.5 \mathrm{~g}$ of the pelletized catalyst. The catalyst was activated at $300{ }^{\circ} \mathrm{C}$ for $2 \mathrm{~h}$ with $\mathrm{N}_{2}$ flow and then allowed to equilibrate with $\mathrm{NH}_{3}$ in the absence of $\mathrm{N}_{2}$ flow at room temperature for $30 \mathrm{~min}$. The excess $\mathrm{NH}_{3}$ was flushed off the reactor with $\mathrm{N}_{2}$ flow. The temperature was then raised in a linear manner at a rate of $20{ }^{\circ} \mathrm{C} / \mathrm{min}$. The desorbed ammonia was trapped in a known excess of $\mathrm{H}_{2} \mathrm{SO}_{4}$ solution at a temperature interval of $100{ }^{\circ} \mathrm{C}$ up to $600{ }^{\circ} \mathrm{C}$. This was then quantified by back titration with $\mathrm{NaOH}$ solution using phenolphthalein indicator.

\section{Results and discussions}

\section{1 X-ray diffraction}

$\mathrm{X}$-ray diffraction profile of powdered polycrystalline samples can provide important information in qualitative phase analysis, quantitative phase analysis, determination of unit cell parameters, study of preferred orientation, and determination of particle size. Figures 1 and 2 show the XRD patterns of cobalt nano ferrite samples calcined at $450{ }^{\circ} \mathrm{C}$ and $750{ }^{\circ} \mathrm{C}$, respectively. X-ray diffractograms of cobalt ferrite samples are in good agreement with the standard values given in the JCPDS data (80-2377). Well defined and broad diffraction peaks from the characteristic crystallographic planes of (220), (311), (400), (422), (511), and (440) indicate the formation of single phase spinel structure. The strongest reflection

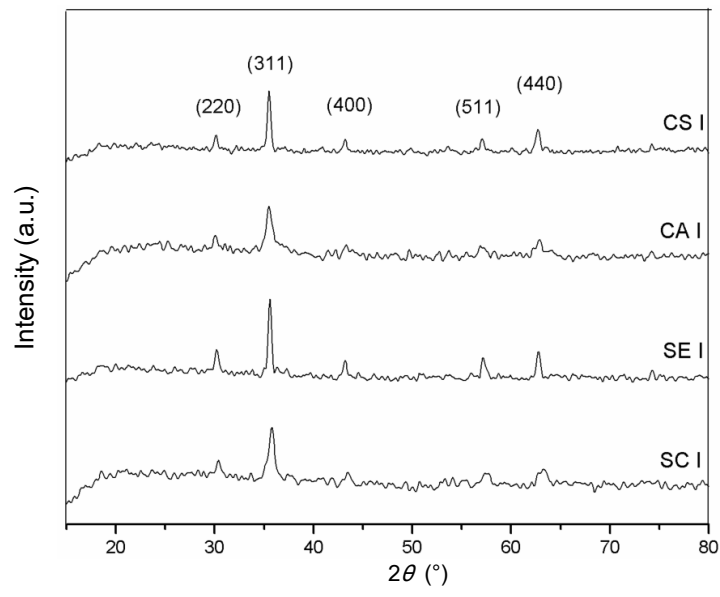

Fig. 1 XRD patterns of $\mathrm{CoFe}_{2} \mathrm{O}_{4}$ nanoparticles calcined at $450{ }^{\circ} \mathrm{C}$.

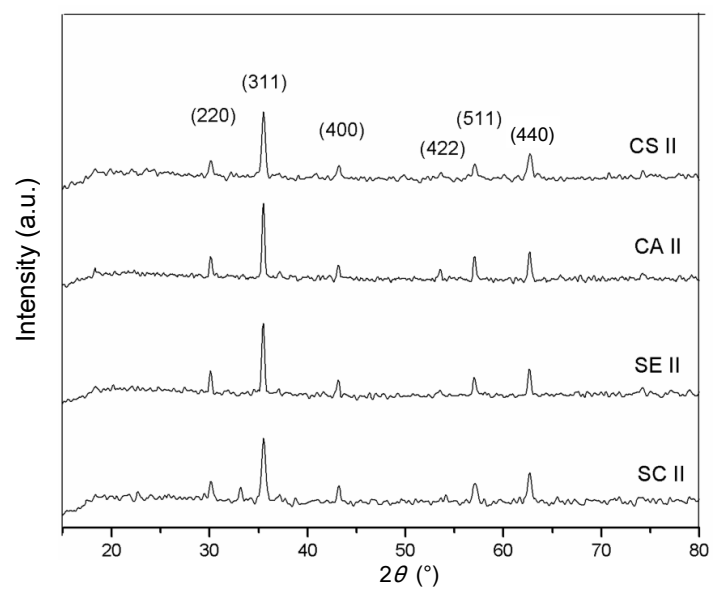

Fig. 2 XRD patterns of $\mathrm{CoFe}_{2} \mathrm{O}_{4}$ nanoparticles calcined at $750{ }^{\circ} \mathrm{C}$.

comes from the (311) plane in all cases, which denotes the spinel phase formation. For samples calcined at $450{ }^{\circ} \mathrm{C}$, the peaks are broad, while for samples calcined at $750{ }^{\circ} \mathrm{C}$, much sharper peaks are observed indicating greater crystallinity of the samples calcined at higher temperature. This suggests the growth of ferrite particles with increase in calcination temperature, which is confirmed by the crystallite size obtained by Scherrer formula (Table 1). Average crystallite sizes fall in the ranges of 7.1-21.1 nm and 30.4-42.1 nm for samples calcined at $450{ }^{\circ} \mathrm{C}$ and $750{ }^{\circ} \mathrm{C}$, respectively. The data on crystallite size suggest that the co-precipitation method is a better route for the synthesis of fine cobalt ferrite nanoparticles compared to sol-gel method. This is probably due to the co-precipitation reaction condition, which favors the simultaneous nucleation of new particles, preventing further crystal growth of particles. Lattice parameters fall in the order of $8.38 \AA$ as expected [19]. X-ray 
Table 1 Average crystallite size $D$, lattice parameter $a$, X-ray density $d_{\mathrm{X}}$, bulk density $d_{\mathrm{B}}$, and porosity $P$ of $\mathrm{CoFe}_{2} \mathrm{O}_{4}$ nanoparticles

\begin{tabular}{cccccc}
\hline Ferrite & $\begin{array}{c}\text { Crystallite } \\
\text { size } D \\
(\mathrm{~nm})\end{array}$ & $\begin{array}{c}\text { Lattice } \\
\text { parameter } a \\
(\AA)\end{array}$ & $\begin{array}{c}\text { X-ray } \\
\text { density } d_{\mathrm{X}} \\
\left(\mathrm{g} / \mathrm{m}^{3}\right)\end{array}$ & $\begin{array}{c}\text { Bulk } \\
\text { density } d_{\mathrm{B}} \\
\left(\mathrm{g} / \mathrm{m}^{3}\right)\end{array}$ & $\begin{array}{c}\text { Porosity } P \\
(\%)\end{array}$ \\
\hline SC I & 21.20 & 8.38 & 5.291 & 2.38 & 69.71 \\
SC II & 30.46 & 8.36 & 5.530 & 2.13 & 56.89 \\
SE I & 13.99 & 8.40 & 5.258 & 1.70 & 67.52 \\
SE II & 42.14 & 8.38 & 5.296 & 2.43 & 63.99 \\
CA I & 7.14 & 8.38 & 5.490 & 1.99 & 63.71 \\
CA II & 32.51 & 8.37 & 5.315 & 2.73 & 48.60 \\
CS I & 14.45 & 8.39 & 5.250 & 1.91 & 62.76 \\
CS II & 35.09 & 8.40 & 5.277 & 2.56 & 61.30 \\
\hline
\end{tabular}

densities of the cobalt ferrite samples vary between 5.25 and $5.53 \mathrm{~g} / \mathrm{m}^{3}$. Bulk density increases at higher calcination temperatures for both sol-gel derived and co-precipitated samples with consequent decrease in porosity. This can be attributed to partial sintering of the synthesized ferrite nanoparticles.

\section{2 FTIR spectroscopy}

Infrared spectroscopy is an important tool to investigate the spinel phase formation of cobalt ferrite nanoparticles. It gives information not only about the positions of bivalent and trivalent metal ions in the spinel lattice, but also about their vibration mode. In ferrites, the IR spectral absorption bands are produced due to the vibrations of the oxygen ions with the cations present in the octahedral and tetrahedral sites in the unit cell. Figures 3 and 4 depict the FTIR spectra of cobalt ferrite nanoparticles calcined at $450{ }^{\circ} \mathrm{C}$ and $750{ }^{\circ} \mathrm{C}$, respectively. The characteristic region of interest for spinel ferrites is the absorption in the range of $400-600 \mathrm{~cm}^{-1}$ [20]. It can be seen from the figures that the IR spectra exhibit two absorption bands in this

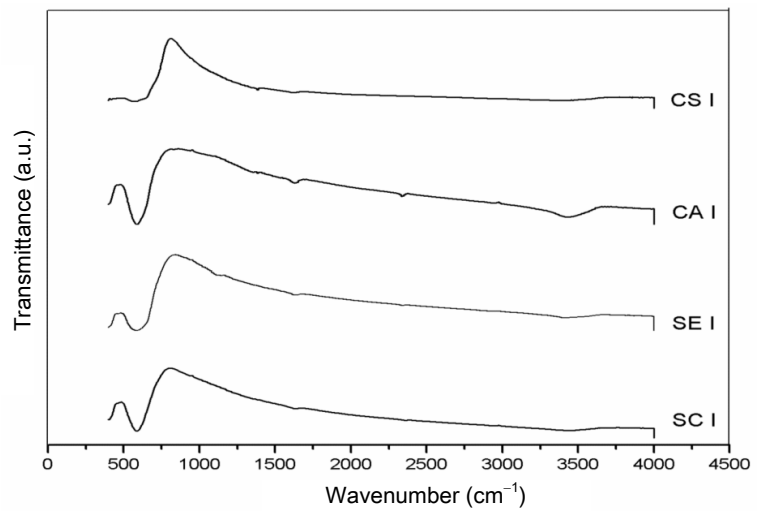

Fig. 3 FTIR spectra of $\mathrm{CoFe}_{2} \mathrm{O}_{4}$ nanoparticles calcined at $450{ }^{\circ} \mathrm{C}$.

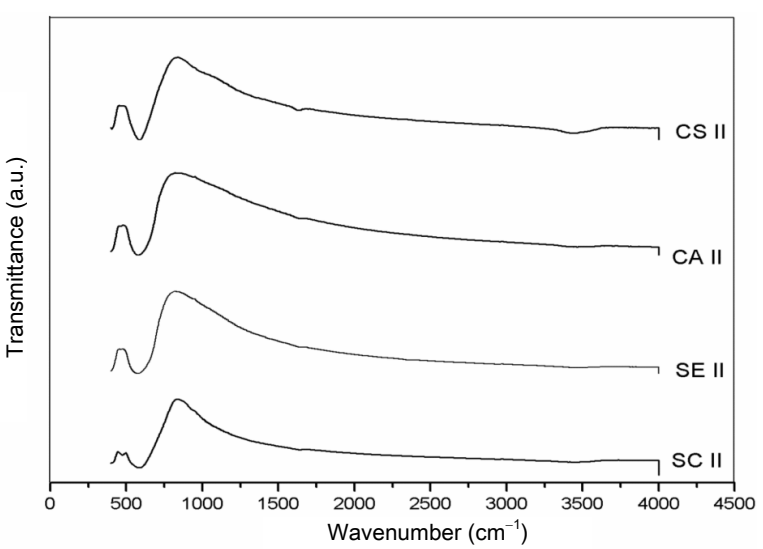

Fig. 4 FTIR spectra of $\mathrm{CoFe}_{2} \mathrm{O}_{4}$ nanoparticles calcined at $750{ }^{\circ} \mathrm{C}$.

region. The high frequency band $v_{1}$ is around $600 \mathrm{~cm}^{-1}$ and the low frequency band $v_{2}$ is around $400 \mathrm{~cm}^{-1}$. Absorption bands observed within this limit reveal the formation of single phase spinel structure having two sub-lattices, tetrahedral (A) site and octahedral (B) site. $\mathrm{CoFe}_{2} \mathrm{O}_{4}$ is an inverse spinel in which $\mathrm{Co}^{2+}$ ions occupy the octahedral sites and $\mathrm{Fe}^{3+}$ ions occupy the tetrahedral sites. The absorption band $v_{1}$ is caused by the stretching vibrations of the tetrahedral metal $\left(\mathrm{Fe}^{3+}\right)$-oxygen bond, and the absorption band $v_{2}$ is caused by the octahedral metal $\left(\mathrm{Co}^{2+}\right)$-oxygen vibrations in octahedral sites [21].

\section{3 Scanning electron microscopy}

Figure 5 depicts the SEM images of different cobalt ferrite nanoparticles calcined at $750{ }^{\circ} \mathrm{C}$. The images reveal the microscopic structure and morphology of ferrite nanoparticles which are in agreement with the XRD results. The images suggest considerable degree of agglomeration of ferrite particles due to its magnetic nature and the union of primary particles held together by weak surface interaction such as the van der Waals forces. It can also be seen that the surface morphology is extremely porous in nature. The samples obtained through the co-precipitation methods (especially using $\mathrm{NaOH}$ as the precipitating agent (CS II)), exhibit better distribution of homogeneous nanoparticles as compared to those from sol-gel auto combustion methods, confirming the results obtained from XRD. Simultaneous nucleation of ferrite nanoparticles takes place during co-precipitation, whereas the second step of crystal formation, viz., crystal growth, is facilitated more during sol-gel method. This can be due to the increased time span required for the completion of sol-gel method. 

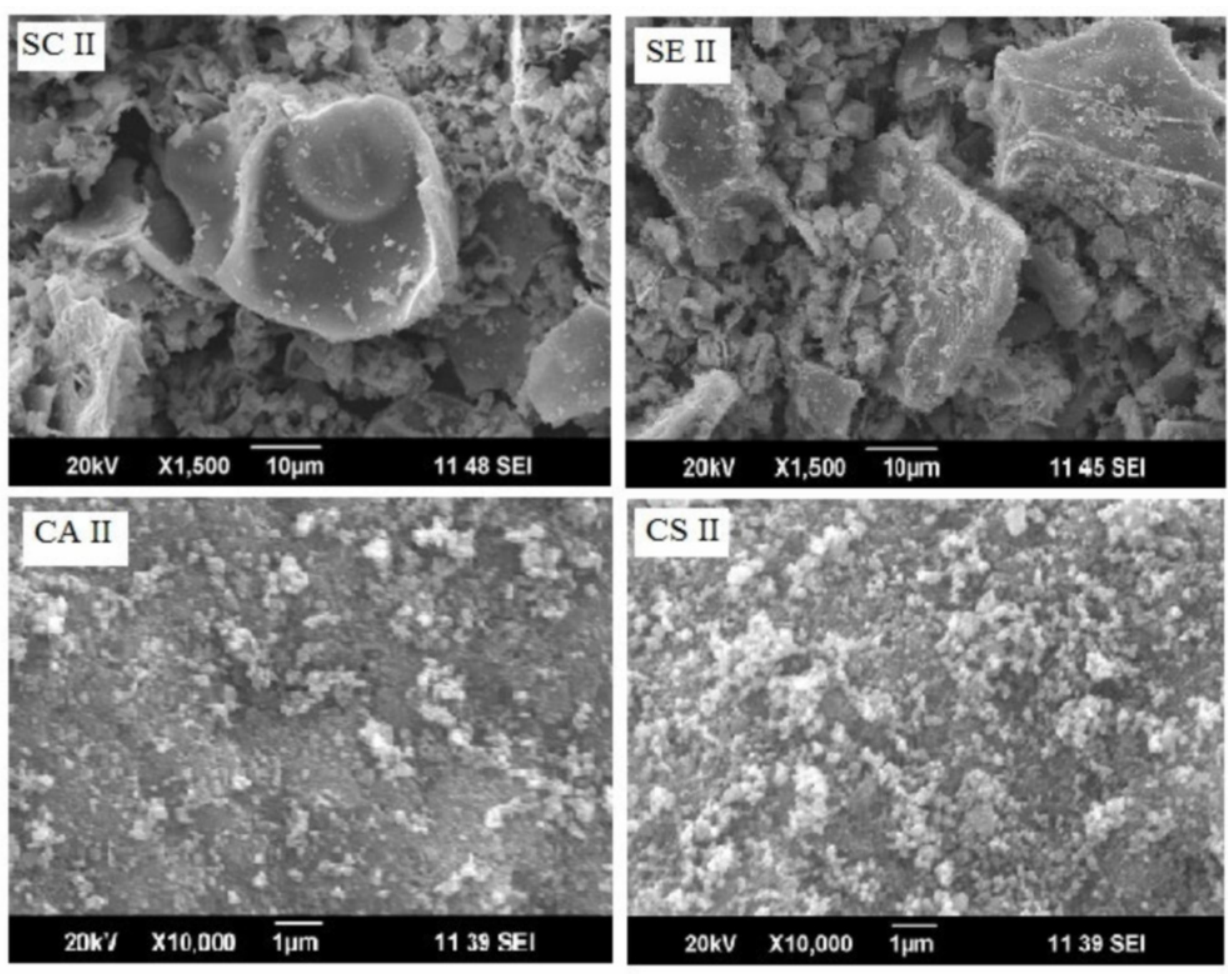

Fig. 5 SEM images of $\mathrm{CoFe}_{2} \mathrm{O}_{4}$ nanoparticles calcined at $750{ }^{\circ} \mathrm{C}$.

\section{4 Magnetic measurements}

Magnetic characterization of the samples was carried out by vibrating sample magnetometer at room temperature with maximum applied field of $15 \mathrm{kOe}$. Typical magnetic hysteresis loops of the samples prepared by sol-gel and co-precipitation methods are shown in Figs. 6 and 7, respectively. The saturation magnetization $\left(M_{\mathrm{s}}\right)$, coercivity $\left(H_{\mathrm{c}}\right)$, and remanence $\left(M_{\mathrm{r}}\right)$ of the samples are shown in Table 2. The saturation magnetization values of the cobalt ferrite samples are found to be lower than the corresponding bulk value of $80.8 \mathrm{emu} / \mathrm{g}$ [22]. The low value of saturation magnetization compared with that of the bulk can be understood on the basis of the core-shell model, which explains that the finite size effects of the nanoparticles lead to canting or non-collinearity of spins on their surface, thereby reducing magnetization [23]. The saturation magnetization increases linearly with the sintering temperature. It is obvious from Table 2 that saturation magnetization value is enhanced for samples sintered at higher temperature, but coercivity and remanence decrease with calcination temperature.

Value of saturation magnetization also depends on grain size and preparation temperature. Increase in $M_{\mathrm{s}}$ with calcination temperature is due to increase in particle size. According to stochastic model for

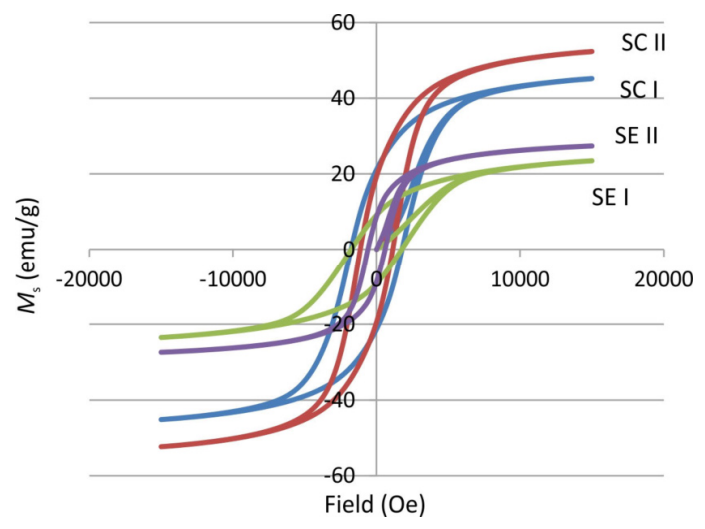

Fig. 6 Hysteresis loops of $\mathrm{CoFe}_{2} \mathrm{O}_{4}$ nanoparticles prepared by sol-gel route.



Fig. 7 Hysteresis loops of $\mathrm{CoFe}_{2} \mathrm{O}_{4}$ nanoparticles prepared by co-precipitation method. 
Table 2 Average crystallite size $D$, saturation magnetization $M_{\mathrm{s}}$, coercivity $H_{\mathrm{c}}$, and remanence $M_{\mathrm{r}}$ of $\mathrm{CoFe}_{2} \mathrm{O}_{4}$ nanoparticles

\begin{tabular}{cccrr}
\hline $\begin{array}{c}\text { Ferrite } \\
\text { sample }\end{array}$ & $\begin{array}{c}\text { Crystallite size } \\
D(\mathrm{~nm})\end{array}$ & $\begin{array}{c}M_{\mathrm{s}} \\
(\mathrm{emu} / \mathrm{g})\end{array}$ & $\begin{array}{c}M_{\mathrm{r}} \\
(\mathrm{emu} / \mathrm{g})\end{array}$ & $H_{\mathrm{c}}(\mathrm{Oe})$ \\
\hline SC I & 21.20 & 44.72 & 21.11 & 1500.56 \\
SC II & 30.46 & 52.09 & 19.19 & 500.16 \\
SE I & 13.99 & 23.33 & 9.10 & 1500.29 \\
SE II & 42.14 & 27.33 & 8.67 & 500.26 \\
CA I & 7.14 & 13.51 & 5.14 & 500.16 \\
CA II & 32.51 & 55.51 & 26.73 & 1500.27 \\
CS I & 14.45 & 32.90 & 14.25 & 1000.28 \\
CS II & 35.09 & 60.71 & 25.71 & 1500.29 \\
\hline
\end{tabular}

variation in magnetic properties with particle size for nano-magnetic particles developed by Chakraverty and Bandyopadhy [24], below a critical diameter at room temperature, the increase in coercivity with increase in particle size in the single domain region has been clarified. A similar variation in $H_{\mathrm{c}}$ is shown by co-precipitation route samples, which implies they are in single domain region. But sol-gel prepared samples exhibit an inverse trend suggesting those particles to be in multidomain region.

\section{5 Temperature programmed desorption of ammonia}

Temperature programmed desorption of ammonia is a convenient technique for assessing the number and distribution of acid sites due to its basicity and small molecular size. For ferrites, the amount of ammonia desorbed from room temperature to $200{ }^{\circ} \mathrm{C}$ is treated as weak, $201-400{ }^{\circ} \mathrm{C}$ as medium, and $401-600{ }^{\circ} \mathrm{C}$ as strong acid sites [25]. The ammonia desorbed at $100{ }^{\circ} \mathrm{C}$ includes some physisorbed ammonia as well, exaggerating the proportion of weak sites. The acid site distribution of the samples as a function of mass is depicted in Fig. 8. It can be deduced from the figure that acidity changes with preparation conditions as well as calcination temperature. Weak acid sites are the most abundant, followed by medium strength sites, while the number of strong acid sites is the least for samples prepared by sol-gel method. Of these, samples prepared using citric acid is more acidic compared to those prepared using ethylene glycol as gelling agent. However, samples prepared by co-precipitation method possess greater number of medium and strong acid sites. Another interesting feature in the figure is that in all cases, the number of weak, medium, and strong acid sites as well as cumulative acidity decrease for samples calcined at higher temperature. This can be accounted by the agglomeration of particles with

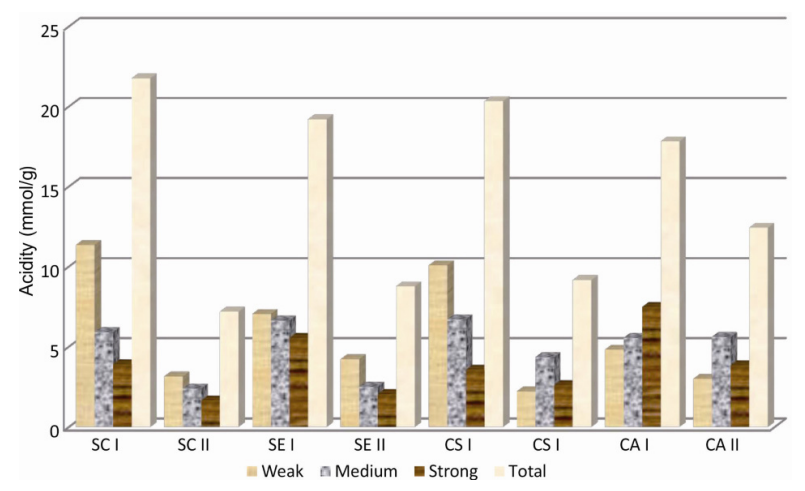

Fig. 8 Surface acid site distribution of the prepared ferrite samples.

consequent increase in crystallite size of the samples at high temperatures as confirmed by XRD and SEM.

\section{Conclusions}

Single phase cobalt ferrite nanoparticles can be prepared by sol-gel and co-precipitation methods. Synthesis conditions as well as calcination temperature have profound influence in the structural, magnetic, and acidic properties of the synthesized ferrites. Average crystallite sizes are in the ranges of 7.1$21.1 \mathrm{~nm}$ and $30.4-42.1 \mathrm{~nm}$ for samples calcined at $450{ }^{\circ} \mathrm{C}$ and $750{ }^{\circ} \mathrm{C}$, respectively. The observed absorption bands in the range $400-600 \mathrm{~cm}^{-1}$ in FTIR spectra confirm the formation of spinel ferrites. SEM images reveal the formation of fine particles within the nanometric range. Magnetic parameters such as saturation magnetization $\left(M_{\mathrm{s}}\right)$, coercivity $\left(H_{\mathrm{c}}\right)$, and remanence $\left(M_{\mathrm{r}}\right)$ of $\mathrm{CoFe}_{2} \mathrm{O}_{4}$ nanoparticles depend on calcination temperature and preparation techniques. Ammonia TPD measurements indicate that weak acid sites predominate medium strength sites, while the number of strong acid sites is the least. In summary, cobalt ferrites prepared by sol-gel and co-precipitation methods can be used as magnetically separable solid acid catalysts.

Open Access: This article is distributed under the terms of the Creative Commons Attribution License which permits any use, distribution, and reproduction in any medium, provided the original author(s) and the source are credited.

\section{References}

[1] Maaz K, Mumtaz A, Hasanain SK. Synthesis and 
magnetic properties of cobalt ferrite $\left(\mathrm{CoFe}_{2} \mathrm{O}_{4}\right)$ nanoparticles prepared by wet chemical route. J Magn Magn Mater 2007, 308: 289-295.

[2] Zhao D, Wu X, Guan H, et al. Study on supercritical hydrothermal synthesis of $\mathrm{CoFe}_{2} \mathrm{O}_{4}$ nanoparticles. The Journal of Supercritical Fluids 2007, 42: 226-233.

[3] Giri AK, Kirkpatric EM, Moongkhmklang P, et al. Photomagnetism and structure in cobalt ferrite nanoparticles. Appl Phys Lett 2002, 80: 2341.

[4] Bueno AR, Gregori ML, Nóbrega MCS. Effect of Mn substitution on the microstructure and magnetic properties of $\mathrm{Ni}_{0.50-x} \mathrm{Zn}_{0.50-x} \mathrm{Mn}_{2 x} \mathrm{Fe}_{2} \mathrm{O}_{4}$ ferrite prepared by the citrate-nitrate precursor method. Mater Chem Phys 2007, 105: 229-233.

[5] Costa ACFM, Silva VJ, Cornejo DR, et al. Magnetic and structural properties of $\mathrm{NiFe}_{2} \mathrm{O}_{4}$ ferrite nanopowder doped with $\mathrm{Zn}^{2+}$. J Magn Magn Mater 2008, 320: e370-e372.

[6] Kurian M, Nair DS, Rahnamol AM. Influence of the synthesis conditions on the catalytic efficiency of $\mathrm{NiFe}_{2} \mathrm{O}_{4}$ and $\mathrm{ZnFe}_{2} \mathrm{O}_{4}$ nanoparticles towards the wet peroxide oxidation of 4-chlorophenol. Reaction Kinetics, Mechanisms and Catalysis 2014, 111: 591-604.

[7] Kundu TK, Mishra S. Nanocrystalline spinel ferrites by solid state reaction route. Bull Mater Sci 2008, 31: 507-510.

[8] Ma R, Wang Y, Zhang C, et al. Microwave absorbing properties of magnesium-substituted $\mathrm{MnZn}$ ferrites prepared by citrate-EDTA complexing method. $J$ Mater Sci Technol 2008, 24: 419.

[9] Kurian M, Nair DS. Synthesis and characterization of nickel zinc ferrite. AIP Conf Proc 2011, 1391: 594.

[10] Sajjia M, Oubaha M, Hasanuzzaman $M$, et al. Developments of cobalt ferrite nanoparticles prepared by the sol-gel process. Ceram Int 2014, 40: 1147-1154.

[11] Feng H, Chen B, Zhang D, et al. Preparation and characterization of the cobalt ferrite nano-particles by reverse coprecipitation. J Magn Magn Mater 2014, 356: 68-72.

[12] Kurian M, Nair DS. On the efficiency of cobalt zinc ferrite nanoparticles for catalytic wet peroxide oxidation of 4-chlorophenol. Journal of Environmental Chemical Engineering 2014, 2: 63-69.

[13] Sorescu M, Diamandescu L, Peelamedu R, et al. Structural and magnetic properties of NiZn ferrites prepared by microwave sintering. J Magn Magn Mater 2004, 279: 195-201.

[14] Jovanović S, Spreitzer M, Otoničar M, et al. $\mathrm{pH}$ control of magnetic properties in precipitation-hydrothermal-derived $\mathrm{CoFe}_{2} \mathrm{O}_{4}$. J Alloys Compd 2014, 589: 271-277.

[15] Liu M, Obi O, Lou J, et al. Strong magnetoelectric coupling in ferrite / ferroelectric multiferroic heterostructures derived by low temperature spin-spray deposition. J Phys D: Appl Phys 2009, 42: 045007.

[16] Abbas M, Rao BP, Islam MN, et al. Size-controlled high magnetization $\mathrm{CoFe}_{2} \mathrm{O}_{4}$ nanospheres and nanocubes using rapid one-pot sonochemical technique. Ceram Int 2014, 40: 3269-3276.

[17] Kurian M, Nair DS. Effect of preparation conditions on nickel zinc ferrite nanoparticles: A comparison between sol-gel auto combustion and co-precipitation methods. Journal of Saudi Chemical Society 2013, DOI: 10.1016/j.jscs.2013.03.003.

[18] Rezlescu N, Rezlescu E, Popa PD, et al. Comparative study between catalyst properties of simple spinel ferrite powders prepared by self-combustion route. Romanian Reports in Physics 2013, 65: 1348-1356.

[19] Vaidyanathan G, Sendhilnathan S, Arulmurugan R. Structural and magnetic properties of $\mathrm{Co}_{1-x} \mathrm{Zn}_{x} \mathrm{Fe}_{2} \mathrm{O}_{4}$ nanoparticles by co-precipitation method. J Magn Magn Mater 2007, 313: 293-299.

[20] Thomas M, George KC. Infrared and magnetic study of nanophase zinc ferrite. Indian J Pure Ap Phy 2009, 47: 81-86.

[21] Sathishkumar G, Venkataraju C, Sivakumar K. Effect of nickel on the structural and magnetic properties of nano structured $\mathrm{CoZnFe}_{2} \mathrm{O}_{4}$. J Mater Sci: Mater El 2011, 22: $1715-1724$.

[22] Gopalan EV, Joy PA, Al-Omari IA, et al. On the structural, magnetic and electrical properties of sol-gel derived nanosized cobalt ferrite. J Alloys Compd 2009, 485: 711-717.

[23] Khot SS, Shinde NS, Ladgaonkar BP, et al. Magnetic and structural properties of magnesium zinc ferrites synthesized at different temperature. Adv Appl Sci Res 2011, 2: 460-471.

[24] Chakraverty S, Bandyopadhyay M. Coercivity of magnetic nanoparticles: A stochastic model. J Phys: Condens Matter 2007, 19: 216201.

[25] Ramankutty CG, Sugunan S, Thomas B. Study of cyclohexanol decomposition reaction over the ferrospinels $\mathrm{A}_{1-x} \mathrm{Cu}_{x} \mathrm{Fe}_{2} \mathrm{O}_{4}(\mathrm{~A}=\mathrm{Ni}$ or $\mathrm{Co}$ and $x=0,0.3,0.5,0.7$ and 1$)$ prepared by 'soft' chemical methods. J Mol Catal A: Chem 2002, 187: 105-117. 